\title{
O grupo multifamiliar como recurso no tratamento dos transtornos alimentares
}

\author{
Multifamily group therapy for patients diagnosed with eating disorders
}

\author{
Maria Amelia da Silva Jaeger ${ }^{1}$, Nedio Seminotti², Olga Garcia Falceto ${ }^{3}$ \\ ${ }^{1}$ Psicóloga. Mestre em Psicologia Clínica. ${ }^{2}$ Doutor em Psicologia, Universidad Autónoma de Madrid, Madrid, Espanha. Professor, Curso de Pós-Graduação em Psicologia, \\ Faculdade de Psicologia, Pontifícia Universidade Católica do Rio Grande do Sul (PUCRS), Porto Alegre, RS. ${ }^{3}$ Doutora, Curso de Pós-Graduação em Medicina: Clínica Médica, \\ Faculdade de Medicina, Universidade Federal do Rio Grande do Sul (UFRGS), Porto Alegre, RS. Professora, Departamento de Psiquiatria, Faculdade de Medicina, UFRGS. \\ Estudo realizado no Departamento de Psiquiatria Infantil, Centro de Atenção Psicossocial (CAPS) - Transtornos Alimentares, Hospital de Clínicas de Porto Alegre \\ (HCPA), Universidade Federal do Rio Grande do Sul (UFRGS), Porto Alegre, RS, e no Programa de Pós-Graduação de Psicologia, Pontifícia Universidade Católica \\ do Rio Grande do Sul (PUCRS), Porto Alegre, RS.
}

\section{Resumo}

Introdução: $\mathrm{O}$ presente artigo é resultado do trabalho sistemático dos autores com grupos multifamiliares de pacientes com diagnóstico de transtorno alimentar (anorexia nervosa, bulimia nervosa e transtorno alimentar não especificado), conjuntamente com seus familiares. As sessões são oferecidas em um hospital público na cidade de Porto Alegre (RS).

Método: Os registros em vídeo de quatro sessões de terapia de grupo multifamiliar foram analisados qualitativamente utilizando-se a técnica de análise de conteúdo.

Resultados: Grupos multifamiliares assim constituídos não foram encontrados na revisão da literatura, e sim apenas relatos de grupos multifamiliares com finalidades exclusivamente psicoeducativas, sem a participação dos pacientes identificados. Na avaliação final, a modalidade de atendimento multifamiliar revelou-se como positiva para o atendimento dos casos avaliados.

Conclusões: A pesquisa demonstrou que esse tipo de abordagem, associado ao tratamento unifamiliar e individual, pode tornar-se uma ferramenta eficaz de tratamento para esses pacientes e suas famílias.

Descritores: Anorexia nervosa, bulimia nervosa, transtornos da alimentação, terapia familiar, grupo multifamiliar.

\begin{abstract}
Introduction: This article is the result of the systematic experience of the authors with multifamily group therapy for patients with a diagnosis of eating disorders (anorexia nervosa, bulimia nervosa and not otherwise specified eating disorders) and their families. Sessions are held at a public hospital in the municipality of Porto Alegre, southern Brazil.

Method: Video recordings of four multifamily group therapy sessions were qualitatively assessed using the content analysis technique.

Results: References to similar multifamily group therapy programs were not found in the literature review; rather, only some reports of multifamily group sessions with exclusively psychoeducational purposes were retrieved, however not including direct patient participation. At the final evaluation, multifamily group therapy was considered to have positive therapeutic outcomes for the patients assessed.

Conclusions: Our study showed that this type of approach, associated with single-family and individual therapy, may become an effective treatment strategy for these patients and their families.

Keywords: Anorexia nervosa, bulimia nervosa, eating disorders, family therapy, multifamily group.
\end{abstract}

\section{Correspondência:}

Maria Amélia Jaeger, Rua João Abbott, 509/202, CEP 90460-150, Porto Alegre, RS, Brasil. Tel.: (51) 3333.3132, (51) 9316.2217. E-mail: ameliajaeger@yahoo.com.br Não foram declarados conflitos de interesse associados à publicação deste artigo.

Copyright (C) Revista de Psiquiatria do Rio Grande do Sul - APRS 


\section{Introdução}

A anorexia nervosa e a bulimia são transtornos que acometem adolescentes e adultos jovens* no mundo inteiro e têm aumentado muito em nosso meio, assumindo proporções epidêmicas ${ }^{1,2}$. Há relatos mundiais sobre o aumento no número de casos, e, no Brasil, particularmente em nossa região, observa-se que essas patologias estão abrangendo todas as camadas sociais e atingindo meninas cada vez mais jovens ${ }^{3}$. Estudos feitos na Europa e nos EUA demonstraram que $70 \%$ das mulheres sentiam-se com sobrepeso e que $79 \%$ das adolescentes sentiam-se gordas ${ }^{1}$. Sukster ${ }^{4}$ conduziu estudos sobre os hábitos alimentares de adolescentes do sexo feminino em uma escola particular de Porto Alegre (RS), constatando taxas de $21,5 \%$ de padrões alimentares anormais e $58 \%$ de insatisfação com a imagem corporal. Pinheiro \& Giugliani ${ }^{5}$ verificaram, numa amostra representativa de toda a população de crianças dessa mesma cidade entre 8 e 11 anos, que $82 \%$ estavam insatisfeitas com sua imagem corporal.

Estudos falam de uma prevalência de $3,06 \%$ para transtornos alimentares em geral, sendo $0,39 \%$ para anorexia nervosa e $0,30 \%$ para bulimia. Para os transtornos alimentares sem outra especificação, foi registrada prevalência de 2,3\%. Dessa forma, vale concluir que este último tipo de transtorno é mais comum, atingindo $3 / 4$ do total de casos detectados na comunidade ${ }^{6}$.

Keski-Rahkonen et al. ${ }^{7}$, em pesquisa recente, alertam que a taxa de prevalência de anorexia nervosa durante a vida pode ser maior do que a relatada em muitos estudos, uma vez que muitos destes são feitos com base em casos tratados. Os autores dizem, ainda, que a maioria das mulheres se recupera clinicamente em 5 anos e, depois disso, costuma encaminhar-se para a recuperação total.

Os transtornos alimentares são considerados doenças de difícil tratamento. Assim, é consenso entre os profissionais de saúde mental que esses pacientes devem ser atendidos por uma equipe multidisciplinar, incluindo a família no processo terapêutico ${ }^{1,8}$, já que os transtornos costumam desorganizar o grupo familiar, complicando seu funcionamento. Em função disso, os estudos atuais estão se concentrando não só em fatores causais e de manutenção, mas também nas formas de tratamento para pacientes e seus familiares. Em alguns casos, as famílias têm sido também identificadas como implicadas na etiologia da doença ${ }^{9}$.

Para um melhor entendimento das questões tratadas neste artigo, são inicialmente trazidos alguns conceitos relevantes da teoria sistêmica, principal aporte teórico utilizado neste estudo, relacionando-os às questões específicas dos transtornos alimentares. Em seguida, dissertamos sobre algumas questões gerais da grupoterapia realizada com esses pacientes e, logo após, focalizamos pontos específicos encontrados na literatura sobre os grupos multifamiliares, buscando obter uma relação entre o que consideramos os eixos norteadores do nosso trabalho: a teoria sistêmica, os transtornos alimentares, a terapia de grupo e os grupos multifamiliares.

\section{Revisão bibliográfica}

A partir dos pressupostos da teoria sistêmica, aprendemos a olhar a família como um sistema biopsicossocial, ou seja, um organismo em si mesmo, cuja identidade excede à soma de seus membros individuais. Estes são afetados e afetam o sistema numa cadeia circular e pertencem também a subsistemas que devem se relacionar adequadamente. Todas essas interações (entre membros e subsistemas) devem respeitar o momento do ciclo de vida da família, sendo mais ou menos flexíveis de acordo com o mesmo ${ }^{10-12}$.

Para que possamos entender os transtornos alimentares, devemos pensar que a anorexia nervosa e a bulimia nervosa constituem patologias complexas, que possuem manifestações clínicas resultantes de múltiplos fatores predisponentes e desencadeantes ${ }^{1,8}$. Dentro dos pressupostos da teoria sistêmica, observamos e entendemos que as famílias nas quais aparecem quadros de anorexia e bulimia situam-se dentro do que Minuchin ${ }^{10}$ define como o perfil das famílias psicossomáticas ${ }^{10,12}$, com padrões de superproteção, aglutinamento, rigidez, conflitos familiares ou de casal não resolvidos, e nas quais o paciente está frequentemente triangulado com os pais. Esses jovens - os pacientes identificados - têm dificuldade para manter um funcionamento autônomo e estabelecer uma identidade própria separada da família ${ }^{1,10}$. Para Falceto et al. ${ }^{11}$, a anorexia nervosa é uma manifestação extrema de uma pessoa dentro de um sistema familiar patologicamente emaranhado.

Focalizando as questões relativas ao atendimento de grupo feito com pacientes psicossomáticos, constatamos que esse tipo de tratamento vem sendo realizado num número cada vez maior, mas que, apesar dos resultados positivos obtidos com sua prática, há ainda poucos estudos dedicados ao tema ${ }^{13}$.

Os grupos multifamiliares - grupos realizados com várias famílias que têm um problema comum a ser tratado, podendo o paciente identificado estar ou não presente - são uma variante da terapia familiar, nos quais os membros podem trabalhar suas habilidades para lidar com os comportamentos relacionados à doença. Esses grupos fomentam a capacitação do insight e oferecem a oportunidade de que os membros aprendam uns com os outros, providenciando suporte e encorajamento, aliviando o sentimento de isolamento e aumentando a comunicação e o funcionamento social dos envolvidos ${ }^{14}$.

Estudos feitos com grupos intensivos de pacientes ambulatoriais com transtornos alimentares e transtornos do co-

\footnotetext{
* Optamos por usar a forma masculina/neutra neste artigo, principalmente devido à presença de um paciente do sexo masculino no grupo descrito. No entanto, é importante alertar para o fato de que a grande maioria de pacientes afetada por transtornos alimentares é do sexo feminino, e que grande parte dos estudos citados no presente artigo avaliou amostras compostas exclusivamente por pacientes do sexo feminino.
} 
mer compulsivo revelaram que esses pacientes aprendem a olhar para suas responsabilidades e capacidades de controle e autodeterminação para lidar com a doença. Os grupos de terapia provocam um sentimento de coesão, suporte e solidariedade entre seus membros, que dividem e compartilham o mesmo estágio de vida e ciclo de patologia ${ }^{15}$.

Quanto aos pais de adolescentes com transtornos alimentares, observa-se que eles mostram altos níveis de sofrimento, o que pode contribuir negativamente para o comportamento disfuncional e patológico de seus filhos. Conforme estudos baseados nos depoimentos de pais, pode-se verificar um alto grau de interesse dos mesmos na obtenção de informações sobre os transtornos alimentares e sentimentos de gratidão pelo recebimento de suporte no manejo com seus filhos ${ }^{16}$.

O conceito primário desse tipo de recurso terapêutico (atendimento multifamiliar) é o da terapia comportamental, encorajando o manejo do sintoma e também facilitando o aprendizado da autodeterminação e responsabilidade em lidar com a doença. Nos pacientes, verifica-se o sentimento de coesão grupal, solidariedade e suporte, pois compartilham semelhante estágio de desenvolvimento e, ainda, os mesmos problemas relacionados ao quadro de transtorno alimentar ${ }^{15}$.

Em um grupo de psicoeducação oferecido a 153 pais de crianças e adolescentes com anorexia e bulimia, foi observado, através do relato dos próprios pais, que eles estavam altamente interessados em obter informações sobre o transtorno de seus filhos e sentiam-se gratos por receber ajuda e suporte no manejo com a doença ${ }^{16}$.

Em trabalho semelhante, uma pesquisa realizada com um grupo de pacientes e familiares com transtornos alimentares indicou que todas as famílias que completaram o programa revelaram uma alta taxa de aceitação do mesmo e apresentaram um decréscimo significativo dos sintomas ${ }^{17}$.

Outro estudo sobre aceitação do tratamento em grupo foi realizado com 16 famílias que participaram de 16 sessões de tratamento de grupo. Após 4 meses, os pais responderam um questionário de satisfação com o tratamento. Entenderam que a intervenção foi positiva e que o tratamento foi fator essencial para o manejo de seus filhos, aumentando suas capacidades como cuidadores, reforçando suas condutas parentais, apoiando-os em suas próprias necessidades de cuidado e contribuindo favoravelmente para o decréscimo de sofrimento com a doença de seus filhos ${ }^{18}$.

\section{Método}

Desde 2002, o Programa de Transtornos Alimentares do Hospital de Clínicas de Porto Alegre (HCPA) atende pacientes que preenchem critérios diagnósticos de anorexia nervosa, bulimia nervosa e transtorno alimentar não especificado, descritos no Manual Diagnóstico e Estatístico de Transtornos Mentais, $4^{\mathrm{a}}$ edição (DSM-IV-TR $)^{19}$.

$\mathrm{O}$ atendimento oferecido pelo programa envolve médicos, psiquiatras, psicólogos, terapeutas familiares, nutricionistas, enfermeiras e recreacionistas, ou seja, uma equipe multidisciplinar que utiliza várias modalidades terapêuticas e que solicita da família e do(a) paciente um envolvimento acentuado com a instituição.

Os grupos multifamiliares são constituídos por cerca de 15 a 20 pessoas, entre pacientes e familiares. São grupos abertos, com sessões de 1 hora e 30 minutos de duração, e realizam-se em intervalos quinzenais. $\mathrm{O}$ grupo de técnicos é integrado por uma coordenadora, uma coterapeuta, um auxiliar de filmagem, um observador e mais um terapeuta de família que estagia no serviço.

$\mathrm{Na}$ coleta de dados para a pesquisa que deu base a este artigo, buscou-se identificar os benefícios desse tipo de atendimento - que já era utilizado empiricamente - como parte de nosso programa. Lançando mão do método qualitativo de análise, pretendeu-se adquirir uma compreensão do material trazido pelos componentes do grupo (pacientes e familiares), identificando, assim, os possíveis pontos fortes e fracos do atendimento do grupo multifamiliar. Nenhum paciente ou família foi excluído do atendimento grupal, já que o próprio serviço faz a triagem na chegada dos casos. Dessa forma, todas as famílias atendidas no programa, que inclui o atendimento multifamiliar, participam dos grupos.

Foram registradas em vídeo seis sessões sucessivas realizadas com os grupos multifamiliares. A filmagem das sessões foi a única modificação que a pesquisa introduziu no grupo, mas é rotina em outras atividades do programa. Embora seis sessões tenham sido filmadas, apenas quatro foram analisadas, em função da repetição e saturação do material. $\mathrm{O}$ número total de falas transcritas integralmente e analisadas nas quatro sessões superou 1.200. Foi utilizado para a análise do material colhido nos grupos o método qualitativo de análise de conteúdo, conforme descrito por Bardin ${ }^{20}$.

A pesquisa foi aprovada pelo Comitê de Ética do HCPA, e todos os participantes assinaram termo de consentimento livre e esclarecido.

\section{Análise e discussão dos resultados}

Através do método de análise de conteúdo ${ }^{20}$, foram identificadas para estudo oito categorias: a doença e suas expressões, a expressão dos sentimentos, a expressão da história pessoal, a manifestação dos conflitos, a expressão do pensamento crítico, o reconhecimento dos progressos, o reconhecimento das responsabilidades e o apoio.

\section{A doença e suas expressões}

Nessa categoria foram elencadas todas as falas dos pacientes e dos familiares que se relacionaram com o entendimento que eles tinham da doença e de como ela se manifestava. Apareceram dúvidas ou incapacidades de manejo dos sintomas, sem que se pudesse verificar diferenças importantes pelo fato do quadro ser de anorexia ou de bulimia. Percebeu-se então, 
que, independentemente das especificidades inerentes a cada quadro, o transtorno alimentar foi visto como central pelos membros do grupo, unindo seus participantes na tentativa de compreender e estabelecer estratégias de manejo efetivas para controlar os sintomas.

Sou a Sabrina, tenho 15 anos e eu tô aqui pra que... a mesma coisa que todo mundo, que é a anorexia e bulimia. (Sabrina)

Nas falas que deram origem a essa categoria, foram identificadas todas as formas da expressão sintomatológica: a privação, a purga, a compulsão, a obsessão pelas dietas e pela contagem de calorias, o transtorno da imagem corporal, as alternativas usadas pelo(a) paciente para escapar da fiscalização da família, as muitas formas utilizadas para desviar a atenção de seus cuidadores em relação à conduta alimentar. É relevante assinalar que a questão central identificada, durante toda ou a maior parte do tempo, foi a do controle. $\mathrm{Na}$ fase inicial da doença, os jovens querem controlar seu corpo, fazê-lo ser como eles desejam e decidem. A partir daí, passam a controlar as calorias, a ingestão de alimentos e até mesmo de líquidos, ou controlam o que ingerem vomitando, usando laxantes, diuréticos, realizando exercícios de forma compulsiva. Num determinado momento, percebe-se que "o jogo vira". De pessoas que controlam seus comportamentos, os pacientes passam a ser controladas pelos mesmos. $\mathrm{O}$ pensamento passa a ter características obsessivas e toda a vida dessas jovens passa a se concentrar em torno da conduta alimentar.

Mello Filho assinala que a doença vale por onde ela se localiza, por sua possibilidade de ficar e, por último, por sua capacidade de destruição. Esse efeito devastador foi amplamente verificado no estudo dessa categoria ${ }^{13}$.

Compreendeu-se, ainda, ampliando-se o problema para o contexto familiar, que os comportamentos terminam comprometendo todo o entorno. Os familiares tentam, primeiro, entender; depois, conter e ajudar. No entanto, são desnorteados pelos comportamentos quase insanos do paciente. Passam também a ser controlados pela doença, tornando-se inoperantes e ineficientes.

\section{A expressão dos sentimentos}

Essa categoria abrangeu todas as falas sobre os sentimentos dos(as) pacientes e de seus familiares que puderam ser expressos no grupo multifamiliar.

Olha, foi um desespero lá em casa. [...] entrei em pânico. (Mãe de Vicente)

Não existe essa história, eu tô mantendo, eu quero manter, não, você tá sempre com medo... (Tatiana)

[...] Não é fácil. Tu chegar a ouvir: o teu filho pode parar o coração a qualquer momento... eu, pai, senti na pele, [...] eu senti na pele 2 meses... (Pai de Vicente)
Novamente citando Mello Filho ${ }^{13}$, a doença, principalmente a doença crônica, atinge a autoestima e todas as perspectivas vitais de sobrevivência do indivíduo, produzindo um efeito avassalador nas capacidades de todos aqueles que se encontram ligados ao paciente.

Em consonância com esse aspecto, percebeu-se o aparecimento de sentimentos de medo e pânico durante todas as fases da doença e do tratamento. Inicialmente, tais sentimentos se expressam na descoberta do transtorno, ou na percepção da gravidade do mesmo, quando pais e paciente "acordam" e se dão conta do risco iminente de morte. Após, centralizam-se nas dificuldades encontradas para aceitar, lidar e combater os sintomas, independentemente de esses serem decorrentes da anorexia ou da bulimia.

Nessa categoria, destacou-se um sofrimento permanente, constante e inequívoco, que atinge a todos, pacientes e familiares envolvidos no processo, bem como sentimentos de gratificação quando iniciam um processo de melhora.

Cheguei aqui, daí a luz se acendeu pra nós. (Mãe de Juliana)

\section{A expressão da história pessoal}

Essa categoria contemplou os relatos de vida trazidos pelos(as) pacientes e seus familiares.

A primeira conexão percebida entre os membros do grupo foi em função do sofrimento e demais sentimentos provocados pelas várias manifestações e ramificações da doença. Essa "ponte" principal, que naturalmente foi o foco maior do grupo, enriqueceu-se com outras questões familiares que puderam ser compartilhadas.

Conforme a literatura, tanto grupos heterogêneos como homogêneos, quando realizados com finalidades terapêuticas, constituem uma importante ferramenta de reflexão, para que pacientes portadores de uma determinada doença possam ter condições de pensar e refletir a respeito de como é ser a pessoa que se é, ter aquela família, aquele cônjuge, aquela vida sexual ou aquele trabalho ${ }^{13}$.

De fato, observou-se que, além da doença, existiam famílias com filhos adolescentes e pais que se deparavam com problemas semelhantes, todos inerentes a essa fase do ciclo vital. Encontramos filhos que lutavam por individualizar-se e que brigavam por espaço e por liberdade.

A Gi já foi muito revoltada comigo, de nós brigarmos muito, ela me agredir muito. Como a Mariana [outra garota do grupo] coloca pra fora essa raiva, a Gi já colocou pra mim também. (Mãe de Giovana)

\section{A manifestação dos conflitos}

Foram localizados nessa categoria os conflitos expressos no "aqui e agora" do grupo, ou seja, aqueles que foram explicitados na dimensão do espaço terapêutico. 
É, mas acontece que vocês só pioraram isso aí o ano passado: tu e ele [pai], piorou mesmo. (Mariana)

Tá, Mariana, [...] elas já sabem o negócio de apartamento... que ela queria morar sozinha. Eu, por enquanto, não posso. (Mãe de Mariana, dirigindo-se a ela)

Em falas semelhantes a essas, foram trazidos para o grupo conflitos intrafamiliares que puderam ser discutidos entre todos os participantes daquele determinado encontro.

Sabemos que famílias de pacientes com transtornos alimentares têm maiores dificuldades de comunicação e de explicitação dos conflitos. No entanto, assim como em outras famílias com filhos adolescentes, muitas coisas que não haviam sido ditas em situações de convívio familiar puderam ser colocadas no espaço grupal, facilitadas pelo apoio do grupo ${ }^{9,10}$.

Mas sabe o que tá faltando em vocês? É diálogo com os filhos de vocês, diálogo... Não adianta só querer exigir, exigir. Elas também estão esperando coisas de vocês. (Vicente)

Cabe salientar, entretanto, que o grupo também forneceu continência para esses conflitos. Ou seja, assim como a raiva podia ser trazida, o grupo também foi capaz de conter a eclosão de situações onde a agressão poderia ser nociva ao processo.

A esse respeito, Zimerman ${ }^{21}$ assinala que a integração de um grupo cumpre a importante função de se comportar como um continente adequado às necessidades e angústias de um e de todos. O autor diz que as pessoas têm, em geral, grande necessidade de buscar suporte social em outras pessoas ou grupos, o que permite que o indivíduo se sinta amado, cuidado, valorizado, mas também contido em suas ansiedades.

\section{A expressão do pensamento crítico}

A emergência dessa categoria nos surpreendeu, em função de que não imaginávamos que pessoas atingidas diretamente por essas doenças pudessem se dar conta da implicação cultural embutida no aparecimento desse tipo de transtorno. Mesmo não conseguindo reagir, notamos que os(as) pacientes percebem o quanto há de engessamento social nas condutas patológicas relacionadas à alimentação, trazendo para o grupo o sentimento de indignação com o mal que toma conta, silenciosamente, de nossa cultura ocidental. Os membros do grupo falaram dos estereótipos criados em relação à imagem corporal, magreza e dietas, ressaltando a força que os mesmos têm no reforço às atitudes alimentares patológicas.

Para ilustrar, num dos grupos realizados, a mãe de uma paciente, Diana, que estava participando de um encontro pela primeira vez, após certificar-se de que a câmera filmadora registraria somente dados para a pesquisa e que não seria utilizada para outros fins, trouxe sua observação sobre um comercial veiculado na época do registro das sessões. Sua fala denunciou:

[...] tem um comercial na televisão, que eu acho que ele tá incentivando as meninas a vomitarem a comida. Aquele que aparece os corpo... né... bem magrinhos, e eu acho que isso a sociedade tem que punir. Tem uma moça, né, e ela faz assim [imita o gesto da moça abaixando-se e curvando-se, como se estivesse vomitando], e passa tão rápido que eu não pude ver se é um banheiro ou é apenas um vestiário... que a gente vê tudo, daí ela fica assim, e força a calça, e daí depois passa a mão na barriga e fecha a calça [imita o gesto, que revela uma atitude de satisfação com o estômago vazio]. Aquilo ali pra quem tem problema de bulimia, eu acho que incentiva, né? (Mãe de Diana)

O comercial em questão estava sendo veiculado por um shopping center na época, e a cena passaria despercebida caso a mãe não a tivesse trazido.

É importante dizer que essa categoria nos permitiu contextualizar e discutir o engessamento social que determina a magreza e a aparência física como ícones. Foi possível visualizar que, apesar do transtorno alimentar, não havia uma cegueira para essas questões, que, ao contrário do que supúnhamos, eram percebidas e avaliadas.

\section{O reconhecimento dos progressos}

Situamos aí o somatório dos processos observados nas categorias anteriores e o que os pacientes e familiares trouxeram sobre suas conquistas e progressos, tanto individuais como familiares.

Percebemos que, em decorrência da dinâmica desse grupo - dinâmica essa que não se constituiu como foco de estudo da pesquisa -, foram emergindo aos poucos nesses indivíduos, pacientes e familiares, as capacidades de enxergarem suas conquistas e de, como indivíduos e como família, vencerem a batalha contra a doença.

Num evidente resgate da autoestima, pacientes reconheceram que podiam controlar a doença, manejando melhor os sintomas, e foram, aos poucos, aceitando com mais facilidade e menor resistência o controle médico e o limite familiar. Famílias foram se apropriando do cuidado com o paciente, conseguindo manejar mais adequadamente as situações que envolviam o(a) filho(a), o que demonstrou a reabilitação das funções parentais.

E a Sabrina... tá tendo muito sucesso, apesar de ser muito poucas consultas, né, ela tá progredindo bastante. [...] A Sabrina agora tá com uma aparência boa. (Mãe de Sabrina)

[...] bem, parei de vomitar, não quero vomitar. Eu evito comer muito, agora a comida não me traz sérios problemas. [...] Agora não, já me conscientizei que ficar só ossinho é... (Sabrina) 


\section{O reconhecimento das responsabilidades}

Nessa categoria foram agrupados os relatos que diziam respeito à forma como todos, pacientes e familiares, começaram a se dar conta da responsabilidade pertinente a cada um nessa cadeia de adoecimento, fazendo o insight de suas "culpas" e de seus movimentos no sentido da manutenção da doença ou da possibilidade de melhora.

Entendemos que a superação da doença está relacionada à capacidade dos familiares de fazerem uma "apropriação" do tratamento de seus filhos. Também estes devem fazer uma "apropriação" da sua necessidade de tratamento e cuidados. Enquanto a família deposita na equipe a responsabilidade de cuidar de seu membro doente, "entregando" esse paciente para que os terapeutas resolvam o problema, as funções parentais permanecem deterioradas, e não há a possibilidade real de resolução do problema. Somente após a família se apropriar da tarefa de ajudar seu filho, e do mesmo também fazê-lo, há condições de um controle sintomatológico e de melhoras significativas.

Essas observações vêm ao encontro do que coloca Ravazzola $^{22}$ no sentido de que, na terapia multifamiliar, as famílias se convocam para ajudar e solucionar um problema que é de um e de todos, o que permite a revisão de crenças e facilita mudanças, salientando que esse é o verdadeiro efeito de rede.

[...] Então é isso que você faz, vomita, fica sem comer, isso é irresponsabilidade. [...] Mas é que nem uma criança que não sabe o que é errado. Não tem responsabilidade. (Tatiana, avaliando suas condutas)

[...] Hoje eu paro e converso [...] hoje eu busco eles. Eu paro, escuto, eu ouço eles. Porque, embora eu estando junto com eles, eu estava ausente [...]. (Pai de Vicente sobre seu comportamento com os filhos)

\section{O apoio}

Última e talvez mais importante categoria estudada, o apoio privilegia o processo básico existente nas interações e no conteúdo das mensagens surgidas no grupo. Vale dizer que, quando os pacientes e familiares falaram sobre as manifestações da doença, sobre os sentimentos pertinentes a cada um, sobre sua história e seus conflitos, quando manifestaram críticas, ou quando reconheceram seus progressos e suas responsabilidades, todas essas falas e seus conteúdos operaram, em cada membro do grupo, processos de identificação, fazendo com que se conectassem uns com os outros e passassem a apoiar-se mutuamente.

Quando Vicente, após ouvir uma menina com anorexia recém-chegada no grupo, relatou sua história de privação alimentar, falou "tudo o mesmo baque", manifestando que a entendia, que se reconhecia nela, fazendo com que a mesma pudesse se sentir, naquele momento, acolhida em suas dificuldades.
O encorajamento mútuo entre as pessoas esteve presente durante a maior parte do tempo nesse grupo. Quando algum membro tinha dificuldades para se colocar, mostrando resistência ou timidez, outros pais ou pacientes tentavam motiválo para que o fizesse:

Aqui é um lugar que a gente pode contar tudo, pode se abrir, pode falar. (Mãe de Juliana)

Percebeu-se que o objetivo de criar um espaço onde as pessoas pudessem falar, comunicar suas ideias e pensamentos e, assim, constituir uma rede de apoio, foi atingido. Houve interesse das pessoas pelo que estava sendo trazido, mesmo que não dissesse respeito às questões alimentares, através de sugestões e fortalecimento de atitudes.

Sentir-se reconhecido, qualificado e acolhido são elementos básicos na experiência grupal. Sobre isso, Foulkes $\&$ Anthony $^{23}$ assinalam com propriedade que ser um membro respeitado e efetivo no grupo, ser aceito e ser capaz de compartilhar e participar do mesmo são exemplos de experiências positivas básicas da vida humana. Os autores complementam ainda que esses são fatores indispensáveis para a saúde mental de qualquer indivíduo.

Ser capaz de se conectar com o sofrimento de alguém é uma das vivências mais ricas a ser experimentada pelo ser humano. Para pessoas que estão desvalidas, apropriarse da capacidade de ajudar, de oferecer sugestões, de ser empático ao que está sendo expresso por alguém tem um significado especial no resgate da autoestima. Esses movimentos apareceram com frequência no grupo aqui descrito. Não só as pessoas puderam encontrar apoio para seu sofrimento psíquico, como também desenvolver sua capacidade de auxiliar outras pessoas, ocupando o papel de terapeuta e obtendo um ganho adicional pela gratificação de poder ajudar seu semelhante.

Percebemos, ainda, que toda a crítica vinda dos pares parece ser melhor "digerida", principalmente quando estes reconhecem ter tido os mesmos comportamentos e não se envergonham de dizê-lo. Vale lembrar aqui Seminotti ${ }^{24}$, que propõe que o grupo deve ser analisado não só como uma identidade única construída pela totalidade dos membros, mas também com base na multiplicidade/diversidade de identidades construídas nos subgrupos formados por alguns membros. Por afinidades ou identificação, alguns membros se subagrupam - nesses grupos multifamiliares, às vezes são filhos com filhos, às vezes pais com pais -, fundando identidades parciais dentro de um mesmo grupo que dão apoio aos membros dos subgrupos no sentido de manifestar com mais facilidade suas opiniões, aconselhamentos e desacordos.

[...] a Renata me perguntou "o que é que tu acha?”, eu disse: "acho que tu não come nada, que tu só come coisa LIGHT”. [...] Ela [Renata] disse "tá criticando?”, eu disse: "Não é uma crítica... eu fazia também, sabe?”. (Tatiana) 
Pensamos que o grupo ofereceu um ambiente receptivo, constante e previsível, e que ofereceu limites seguros, sendo possível perceber o sentimento de "pertencer ao grupo".

O grupo confrontou os membros - o apoio também se deu por essa via. Fez com que o outro pudesse repensar o que falava, aconselhando-o a "ver-se do outro lado do espelho". No relato a seguir, alguns trechos que mostram o interesse, a empatia e, também, a confrontação.

Será que já não tá na hora: já o pai mudou, a mãe mudou um pouco, de tu mudar também? Será que é só eles que têm que mudar? (Mãe de Débora)

Mas é que eu mudei. Tanto é que eu mudei, que eu sofro com isso. (Mariana)

Então tu não mudou! (Mãe de Débora, para Mariana)

Finalizamos a discussão dessa categoria, uma das mais importantes encontradas nesse processo de análise, lembrando a colocação de Zimerman ${ }^{21}$ de que a integração de um grupo cumpre a importante função de se comportar como um continente adequado às necessidades e angústias de um e de todos. Diz o autor que as pessoas têm, em geral, grande necessidade de buscar suportes sociais em outras pessoas, grupos e instituições, sendo que esse suporte faz com que o indivíduo se sinta amado, cuidado, valorizado, mas também contido em suas ansiedades.

\section{Conclusões}

Apoiados em seu subgrupo de pertencimento, os pacientes conseguiram colocar seus sentimentos aos demais familiares, falando sobre seus temores e sobre como não conseguiam ter controle sobre seus pensamentos e comportamentos. Por outro lado, os pais, apoiados pelo subgrupo parental, colocaram também suas dificuldades, assumindo suas incapacidades em lidar com o transtorno. Compartilharam dúvidas, medos e questionamentos. Relatando histórias semelhantes, foram descobrindo que passagens comuns os aproximavam. Não se observou, no entanto, a formação de subgrupos de pacientes com anorexia e pacientes com bulimia. As diferenças de sintomatologia manifestas em cada doença foram trazidas frequentemente, mas não provocaram a formação de subgrupos constituídos por membros de cada patologia. Muito pelo contrário, pareceu haver uma prepon- derância de interesse pelas semelhanças, que foram reconhecidas em muitas das características comuns aos pensamentos e comportamentos disfuncionais.

$\mathrm{O}$ oferecimento de modelos apareceu em vários momentos do funcionamento do grupo, não somente naqueles dados por pacientes de melhor evolução a pacientes mais graves, mas também nos modelos que as famílias que foram capazes de obter sucesso na tentativa de recuperação de seu(ua) filho(a) puderam oferecer para outras famílias que mostravam mais incapacidade de manejo.

Todas essas questões reforçam nossa ideia de que, diferentemente daquilo que é descrito na literatura, a saber, a realização de grupos de pacientes ou de familiares separados por critério diagnóstico (anorexia ou bulimia) e, principalmente, com finalidades psicoeducativas ${ }^{25-27}$, podemos trabalhar com ambos de forma conjunta, sem que precisemos separá-los, tratando essas pessoas dentro do enfoque da terapia sistêmica, com resultados bastante positivos.

\section{Limitações do estudo}

Ressalta-se que este trabalho não teve como finalidade estudar o funcionamento dinâmico da terapia de grupo multifamiliar, pois a intenção da pesquisa foi, especialmente, investigar os mecanismos de ajuda do grupo no tratamento dos transtornos alimentares. Com relação a esse aspecto, pareceu-nos que o aporte oferecido constitui uma boa ferramenta no auxílio a esses pacientes e suas famílias, permitindo respaldar uma estratégia terapêutica utilizada até hoje no serviço. Outrossim, cabe sublinhar que, no tratamento desse tipo de paciente, o grupo multifamiliar foi visto como mais um recurso, e não como o único, não tendo sido utilizado isoladamente. Ele fez, isto sim, parte de um trabalho que é realizado sempre em equipe, e que dá conta, através da terapia individual e de grupo, da terapia unifamiliar, do acompanhamento nutricional, clínico e medicamentoso, de todos os aspectos referentes a uma patologia que é multifatorial ${ }^{25-27}$ e que, portanto, exige uma abordagem multidisciplinar. Vale ainda ressaltar que, como toda pesquisa que utiliza o método qualitativo, não podemos partir para generalizações, devendo-se entender que os resultados, que nos pareceram promissores, foram obtidos para o grupo e momento específicos aqui descritos. Faz-se a ressalva para a necessidade de mais pesquisas, sobretudo por tratar-se de patologia de difícil tratamento e de alta prevalência no cenário atual ${ }^{6}$. 


\section{Referências}

1. Herscovici CR, Bay LA. Escravidão das dietas. Porto Alegre: Artes Médicas; 1997.

2. Nunes MA, Bagatini LF, Abuchaim AL, Kunz A, Ramos D, Silva JA, et al. Distúrbios da conduta alimentar: considerações sobre o teste de atitudes alimentares (EAT). Rev ABP-APAL. 1994;16:7-10.

3. Jaeger MA. O grupo multifamiliar como recurso no tratamento dos transtornos alimentares [dissertação]. Porto Alegre: Pontifícia Universidade Católica do Rio Grande do Sul; 2003.

4. Sukster E. Avaliação da imagem corporal e da função visoconstrutiva em adolescentes femininas com padrão de preocupação exagerada dos hábitos alimentares [dissertação]. Porto Alegre: Universidade Federal do Rio Grande do Sul; 1998.

5. Pinheiro AP, Giugliani ER. Body dissatisfaction in Brazilian schoolchildren: prevalence and associated factors. Rev Saude Publica. 2006;40(3):489-96.

6. Machado P, Machado B, Gonçalves S, Hoek H. The prevalence of eating disorders not otherwise specified. Int J Eat Disord. 2007;40(3):212-7.

7. Keski-Rahkonen A, Hans W, Susser ES, Linna MS, Sihvola E, Bulik CM, et al. Epidemiology and course of anorexia nervosa in the community. Am J Psychiatry. 2007;164:1259-65.

8. Cordás TA. Transtornos do comportamento alimentar. In: Taborda JG, Lima PP, Busnello E, orgs. Rotinas em psiquiatria. Porto Alegre: Artes Médicas; 1996. p. 208-18.

9. Lemmon CR, Josephson AM. Family therapy for eating disorders. Child Adolesc Psychiatr Clin N Am. 2001;10:519-42.

10. Minuchin S. Famílias: funcionamento e tratamento. Porto Alegre: Artes Médicas; 1990.

11. Falceto OG, Rosa JC, Tetelbom M, Sukster E, Benetti SP, Cohen SC, et al. Anorexia nervosa: querem que eu viva? Rev ABP-APAL. 1993;15:11-6.

12. Minuchin S, Rosman BL, Baker L. Psychosomatic families: anorexia nervosa in context. Cambridge: Harvard University Press; 1978.

13. Mello Filho J. Grupoterapia com pacientes somáticos. In: Zimerman DE. Como trabalhamos com grupos. Porto Alegre: Artes Médicas; 1997.
14. Colahan M, Robinson PH. Multi-family groups in the treatment of young adults with eating disorders. J Fam Ther. 2002;24(1):17-30.

15. Michler P, Wolter FA, Linder M. [Intensive outpatient group treatment for adolescents with eating disorders]. Prax Kinderpsychol Kinderpsychiatr. 2007;56(1):19-39.

16. Hagenah U, Vloet T. [Parent psychoeducation groups in the treatment of adolescents with eating disorders]. Prax Kinderpsychol Kinderpsychiatr. 2005;54(4):303-17.

17. Salbach H, Bohnekamp I, Lehmkuhl U, Pfeiffer E, Korte A. Family-oriented group therapy in the treatment of female patients with anorexia and bulimia nervosa: a pilot study. Z Kinder Jugendpsychiatr Psychother. 2006;34(4):267-74.

18. Zucker NL, Marcus M, Bulik C. A group parent-training program: a novel approach for eating disorder management. Eat Weight Disord. 2006;11(2):78-82.

19. American Psychiatric Association. Manual diagnóstico e estatístico de transtornos mentais, $4^{\mathrm{a}}$ edição (DSM-IV-TR). Porto Alegre: Artmed; 2002.

20. Bardin L. Análise de conteúdo. Lisboa: Edição 70; 1991

21. Zimerman DE. Fundamentos básicos das grupoterapias. Porto Alegre: Artes Médicas; 2000

22. Ravazzola C. A família como grupo e o grupo como família. In: Zimerman D, Osorio LC, eds. Como trabalhamos com grupos. Porto Alegre: Artes Médicas; 1997.

23. Foulkes SH, Anthony EJ. Psicoterapia de grupo: a abordagem psicanalítica. Rio de Janeiro: Biblioteca Universal Popular; 1967.

24. Seminotti N. Primero la semejanza y luego las diferencias. Clin Anal Grupal. 2001;23(86):79-90.

25. Geist R, Heinmamaa M, Stephens D, Davis R, Katzman DK. Comparison of family therapy and family group psychoeducation in adolescents with anorexia nervosa. Can J Psychiatry. 2000;45:173-8.

26. Rosenvinge JH. Group therapy for anorexic and bulimic patients. Some aspects on the conduction of group therapy and a critical review of some recent studies. Acta Psychiatr Scand Suppl. 1990;361:38-43.

27. Dare C, Eisler I. A multi-family group day treatment programme for adolescent eating disorder. Eur Eat Disord Rev. 2000;8:4-18. 